\title{
Investigation of Entrance and Wall Dynamics of the High-Flux Gas-Solid Riser Using Statistical Analysis of Solids Concentration Signals
}

\author{
Justin M. Jeremiah1, Samwel V. Manyele1, Abraham K. Temu1', Jesse-X. Zhu² \\ ${ }^{1}$ Department of Chemical and Mining Engineering, University of Dar es Salaam, Dar es Salaam, Tanzania \\ ${ }^{2}$ Department of Chemical and Biochemical Engineering, University of Western Ontario, London, Canada \\ Email: jeremiahjmj@udsm.ac.tz, smanyele@udsm.ac.tz, atemu@udsm.ac.tz, jzhu@uwo.ca
}

How to cite this paper: Jeremiah, J.M., Manyele, S.V., Temu, A.K. and Zhu, J.-X. (2019) Investigation of Entrance and Wall Dynamics of the High-Flux Gas-Solid Riser Using Statistical Analysis of Solids Concentration Signals. Engineering, 11, 167-187. https://doi.org/10.4236/eng.2019.113013

Received: September 12, 2018

Accepted: March 26, 2019

Published: March 29, 2019

Copyright $\odot 2019$ by author(s) and Scientific Research Publishing Inc. This work is licensed under the Creative Commons Attribution-NonCommercial International License (CC BY-NC 4.0). http://creativecommons.org/licenses/by-nc/4.0/

\begin{abstract}
Statistical analysis of the entrance and wall dynamics of a high-flux gas-solid riser was done using solid concentration time series data collected from a 76 $\mathrm{mm}$ internal diameter and $10 \mathrm{~m}$ high riser of a CFB system with a twin-riser operated at 4.0 to $10.0 \mathrm{~m} / \mathrm{s}$ gas velocity and 50 to $550 \mathrm{~kg} / \mathrm{m}^{2}$ s solids flux. Spent fluid catalytic cracking catalyst particles with $67 \mu \mathrm{m}$ mean diameter and density of $1500 \mathrm{~kg} / \mathrm{m}^{3}$ together with $70 \%$ to $80 \%$ humid air was used. Solid concentration data were analysed using code prepared using FORTRAN 2008 to get statistical parameters and plot their profiles. Results obtained show that the gas-solid suspension flow in the riser is dominated by low solid concentration in the centre region and high solid concentration in the wall region which forms a core-annulus flow structure. The mean solid concentration in the wall region decreases with riser height from the dense bottom section to less dense in the fully developed flow section at the top of the riser. The gas-solid suspension flow in the centre region is dominated with uniform flow structure while the wall region is dominated with high fluctuations in solid concentration. Further, it was found that the entrance and developing flow sections of the riser exhibit high flow non-uniformities than the fully developed flow section of the riser. The flow non-uniformities in the entrance and developing flow section increase with increase in superficial gas velocity at constant solid flux. The wall region, from the entrance to the top sections of the riser along the axial direction exhibits both dilute and dense suspension flow.
\end{abstract}

\section{Keywords}

Entrance Section, Wall Region, Statistical Analysis,

Flow Non-Uniformities, Radial Non-Uniformity Index 


\section{Introduction}

The advantages of circulating fluidized bed (CFB) riser over other reactors in various industrial applications have resulted to the continued substantial growth of their usage [1] [2]. These reactors provide large interfacial area, high degree of mixing and temperature uniformity with high efficiency and flexibility. However, these reactors are disadvantaged with solid backflows, flow non-uniformities and formation of clusters in some locations [1] [2]. These advantages reduce the efficiency of the gas-solid contacts and selectivity in the CFB riser reactors [1] [2]. Despite of the information found in literatures on their applications and process operations, some information on reactor dynamics especially in the wall region and entrance section is still limited. The gas-solid dynamics in these reactors play an important role in describing their performance [2]. The wall region and the entrance section are locations of the riser with strong interactions between the gas and solid phases [3] [4]. But it is also in these locations where the profiles of solids concentration and the gas-solid suspension flow velocities evolve [3] [4]. Thus, the comprehensive understanding of the complex dynamics exhibited by the gas-solid flow in the wall region and entrance section is very crucial to the proper designing of these reactors and subsequent process operations. The knowledge of the gas-solid flow dynamics can be utilized to improve the reaction characteristics in these reactors and increase their productivity [5] [6].

Studies have shown that variations of solid concentrations in the gas-solids suspension flow systems in the CFB risers are one of the disadvantages that elevate gas-solid flow non-uniformities [1]. Thus characterizing the temporal variations of solid concentration particularly in the wall region and entrance section of the riser as affected by the gas velocity is paramount to the understanding of the systems dynamics. The common approach employed to investigate and provide a broad insight of the gas-solid flow dynamics in gas-solid flow systems like the CFB riser and downer is the Time Series Analysis (TSA) which uses statistical, spectral and chaos analyses of the measured signals [7] [8].

While various studies couple some statistical analysis with other approaches like spectral and or chaos analysis, this paper employs and presents a comprehensive statistical analysis of the temporal variations of solid concentration signals by basing the analysis in the wall region and entrance section in comparison to the centre region of the CFB riser. The paper has reviewed and used microscopic or time dependent and macroscopic or averaged parameter statistical methods related to CFB dynamics. Due to many concepts in use, more diverse results are presented in this paper because solid concentration data were collected across several radial positions (11) and axial elevations (8) which necessitated the use of taller high-flux CFB $(10 \mathrm{~m})$. Thus, results are presented in various subsections using Mean, Standard deviations, Skewness, Kurtosis, Intermittent Index, Average Absolute Deviation, Coefficient of Variation, Radial Non-uniformity Index and Probability Density Function. 


\section{Literature Review}

\subsection{Application of Statistical Tools to Analyse Gas-Solid Flow Dynamics}

Statistical analysis is one of the time-series analysis (TSA) techniques that employ various tools or parameters to investigate solid distribution in the gas-solid flow systems. Literatures show that solid particles distribution in the riser reactor during the gas-solid flow operations is highly influenced by solids backflows especially in the wall regions, formation of clusters and flow non-uniformities in the radial and axial profile [1] [2]. Studies have shown that formation of clusters in these reactors is highly attributed to the inter-particle forces, particle-wake interactions, wall-particle interactions and non-uniform introduction of particles [1]. Solid backflows is also related to the loss of momentum which is attributed to various interaction forces. Flow non-uniformities in the axial and lateral directions are an intrinsic characteristic of the gas-solid up-flow riser fluidization systems [9] [10]. Further, it is shown that even the influence of such factors as solid backflows, clusters formation and flow non-uniformities are depicted through statistical analysis of the solid concentration.

Literatures present various studies that investigated the axial and radial distribution of solids in the gas-solid suspension flow system in circulating fluidized bed (CFB) risers and downers using statistical analysis. The study by Manyele et al. [1] analysed the solid distribution in the CFB riser using statistical analysis of the solid concentration. Further, Manyele et al. [7] employed statistical analysis coupled with spectral and chaos analyses to study the microscopic flow structure of a CFB Downer using solid concentration signals. Results in these studies showed the capability and suitability of statistical tools in analysing the gas-solid flow systems other than the CFB riser. Johnson et al. [11] coupled statistical tools like the mean, standard deviations, skewness and kurtosis with spectral and chaos analyses to describe the flow behaviours in fluidisation operation using pressure fluctuation measurements. Also studies by Zhu and Zhu [12] employed statistical analysis to investigate the flow structures in the bottom region of the CFB riser. Further, statistical analysis has also been used in the analysis of gas-solid flow dynamics using pressure fluctuations measurements. Studies by Lukosi et al. [13] employed statistical analysis to study pressure fluctuations in the circulating fluidized bed riser reactor. Further, Qiu et al. [8] used statistical analysis to investigate the gas-solid flow characteristics in CFB reactor with annular combustion chamber using pressure measurements. All these studies have shown the suitability of employing statistical analysis in studying the gas-solid flow systems using both solid concentrations and pressure fluctuations. Further, clusters in gas-solid flows in CFB risers can be identified through techniques which base on statistical analysis [4] [14] [15].

The solid distribution in the CFB riser and downers has been of interest in various studies since it affects various aspects of production process such as rate of heat and mass transfer which in turn affects the rate of chemical reactions and 
overall product yield. It is shown that the axial and radial flow structures in the CFB riser reactor is highly influenced by the operating conditions of the solid flux and superficial gas velocity [1] [16]. At low solid flux, below $400 \mathrm{~kg} / \mathrm{m}^{2} \mathrm{~s}$, the radial solid distributions have been shown to be non-uniform with dilute or low solid concentration particularly in the centre region of the riser. Then solid concentration increases slowly in the middle region to dense concentration towards the wall of the riser reactor [17]. This flow behaviour results in what is known as a "Core-annulus" flow structure [3] [7] [16]. However, at higher solid fluxes, $G_{s}$ $\geq 700 \mathrm{~kg} / \mathrm{m}^{2} \mathrm{~s}$, the flow structures changes to concave or parabolic curve form with higher concentration towards the wall [16]. Axially, at low solid fluxes such as below $100 \mathrm{~kg} / \mathrm{m}^{2} \mathrm{~s}$, the solid concentration profiles are approximately exponential shaped [16]. As the solid flux increases the axial profiles becomes non-uniform with higher solid concentration in the entrance section forming a belly shaped profile, which decreases to dilute or low concentration in the top sections of the CFB riser reactor [1] [12] [16]. Further, solid segregation in the axial and radial directions of the riser has been observed in the gas-solid flow [18].

\subsection{Statistical Tools Used in the Analysis of Gas Solid Flow Dynamics}

The most used statistical tools or parameters in the analysis of solid concentration includes the Mean, Standard Deviations, Skewness, Kurtosis, Coefficient of Variation, Intermittent Index, Average Absolute Deviation $(A A D)$, Radial NonUniformity Index $(R N I)$ and Probability Density Functions (PDF).

In gas-solid CFB riser operation, the mean or average solid concentration gives the average distribution of solid particles in the gas-solid flow suspension around the sampling point [1] [7] [8] [12] [16] [19]. The standard deviation measures the deviations from the average values [8] [19] [20] [21] [22]. It gives a measure of the amplitude of the signal in question [11]. But also it gives the dispersion or spread of values in the probability density function (PDF). Skewness is the third moment of the distribution that gives symmetrical properties of a particular distribution [7] [11]. In gas-solid flow Skewness is used to indicate the symmetrical properties of the solid concentration distribution in comparison to the mean value [8]. It also measures the degree of asymmetry of PDF around its mean. In regards to gas-solid flow, a positive or higher value indicates a segregated gas-solid suspension giving a PDF with relatively longer tail towards higher solid concentration or right tailed PDF while a negative value indicates a skewed data to the left or suspension flow with lower solid concentration than the mean value [7] [8]. Further, asymmetric distribution has zero Skewness while a positive Skewness indicates the right skewed distribution which indicates the flow with higher solid concentration than the mean value [7] [8] [11].

Kurtosis is the fourth moment of the data signal which indicates the flatness of the distribution in comparison to the normal distribution. It shows whether data are peaked or flat when compared with a normal distribution [8] [11]. A negative or low value indicates a flat distribution and a positive or high value indicates a peaked distribution [8]. The Intermittent Index is the parameter used 
in gas-solid flow to quantify solid flow fluctuations and the extent of segregation of the gas-solid suspension [7]. It is used to study the microstructure of the gas-solid suspension. A perfect uniform local suspension flow give a value of zero while a cluster flow with particles segregated into clusters gives a value of one. In general high Intermittent Index shows a highly segregated flow while lower intermittent index shows a more uniform flow and less time dependent gas-solid suspension [7] [22]. When the Intermittent Index is one, the gas-solid flow suspension is termed as "ideal cluster flow" while a perfect Core-annulus flow behaviour; the intermittent index is equal to zero [16].

Coefficient of variation is a measure of dispersion or scattering tendency of a probability distribution or frequency distribution [19] [23]. It is the measure of the spread or relative variability of a distribution that expresses standard deviation as a percentage of the mean [19]. The $C V$ of a single variable describes the dispersion of a distribution of that variable in a way that does not depend on the variable's measurement unit. The higher the $C V$, the greater is the dispersion or variation in the variable [19]. In gas-solid suspension flow, the coefficient of variation quantifies the level of fluctuations from the mean. The $R N I$ of a given parameter is defined as the standard deviation of its values in the radial direction, normalized by the maximum possible standard deviation for the same parameter with the same average cross-section value [16] [21]. The $R N I$ measures the extent of radial variations of the flow parameters such as the solid concentration. The higher the value the less uniform is the flow and vice versa. The $R N I$ ranges between 0 and 1; the larger values indicate less uniform distribution structure while less values indicates uniform flow [16] [21].

The $A A D$ describes the variability of data distribution. As far as the gas-solid flow is concerned the $A A D$ is used to indicate the level of gas-solid flow fluctuations in the CFB riser [11] [18] [23]. The PDF profiles are used to identify the scattering tendency of the gas-solid suspension flow [1] [7] [22]. In gas-sold suspension flow, the PDF of the solid concentration reveals the scattering tendency of the solids in the suspension [7]. The PDF profiles give different shapes in different spatial locations for different operating conditions. This makes PDF a good tool in identifying different states of the gas-solid flow dynamics. A single peaked PDF indicates a single phase dominated flow. While the two peaked PDF profiles represents the existence of the dilute and dense phases. Further, a wider and flatter PDF shows mixed flow state or suspension flow segregation while a tall and narrow PDF indicates less segregated flow [7] [12].

Literature review shows that most of statistical analysis were developed and used separately. This paper combines all parameters to analyse the same data allowing for insight comparison of results and hence deeper understanding of the dynamics.

\section{Methodology}

\subsection{Data Collection}

Solid concentration data signals were collected from a $76 \mathrm{~mm}$ internal diameter 
riser of a CFB system with a twin-riser having 76 and $203 \mathrm{~mm}$ internal diameters and $10 \mathrm{~m}$ high shown in Figure 1 . The riser was operated at 50 to $550 \mathrm{~kg} / \mathrm{m}^{2} \mathrm{~s}$ solids flux and 4.0 to $10.0 \mathrm{~m} / \mathrm{s}$ gas velocity. Fluid catalytic cracking catalyst particles with $67 \mu \mathrm{m}$ mean diameter and density of $1500 \mathrm{~kg} / \mathrm{m}^{3}$ were used. A $70 \%$ to $80 \%$ humid air was used for transporting the solid particles. Signals were sampled from eight (8) axial levels (i.e. $Z=0.98,1.52,2.73,3.96,5.13,6.34,8.74$, and $9.42 \mathrm{~m}$ ) and 11 radial points (i.e. $r / R=0.00,0.16,0.38,0.50,0.59,0.67,0.74,0.81$, $0.87,0.92$, and 0.98 ) at each level where $r / R$ is the normalized radial distances from the centre to the wall of the riser. To each point, 29,100 data points of solid concentration were sampled in 30 seconds using optical fibre probe at $970 \mathrm{~Hz}$.

\subsection{Data Processing and Statistical Profiles Generation}

The solid concentration data signals obtained from the experiment were statistically analysed using codes prepared in FORTRAN 2008 to determine the Mean $\left(\overline{\varepsilon_{s}}\right)$, Standard deviation $\left(\sigma\left(\varepsilon_{s}\right)\right)$, Skewness $\left(S_{k}\right)$, Kurtosis $\left(K_{u}\right)$, Intermittent Index $(\gamma)$, Average Absolute Deviation $(A A D)$, Coefficient of Variation $(C V)$, Radial Non-uniformity Index $(R N I)$ and Probability Density Functions (PDF). The radial and axial profiles of the computed parameters were plotted and examined. Then interpretation was accomplished by relating various features of the profiles to the gas-solid flow dynamics in the circulating fluidized bed riser.

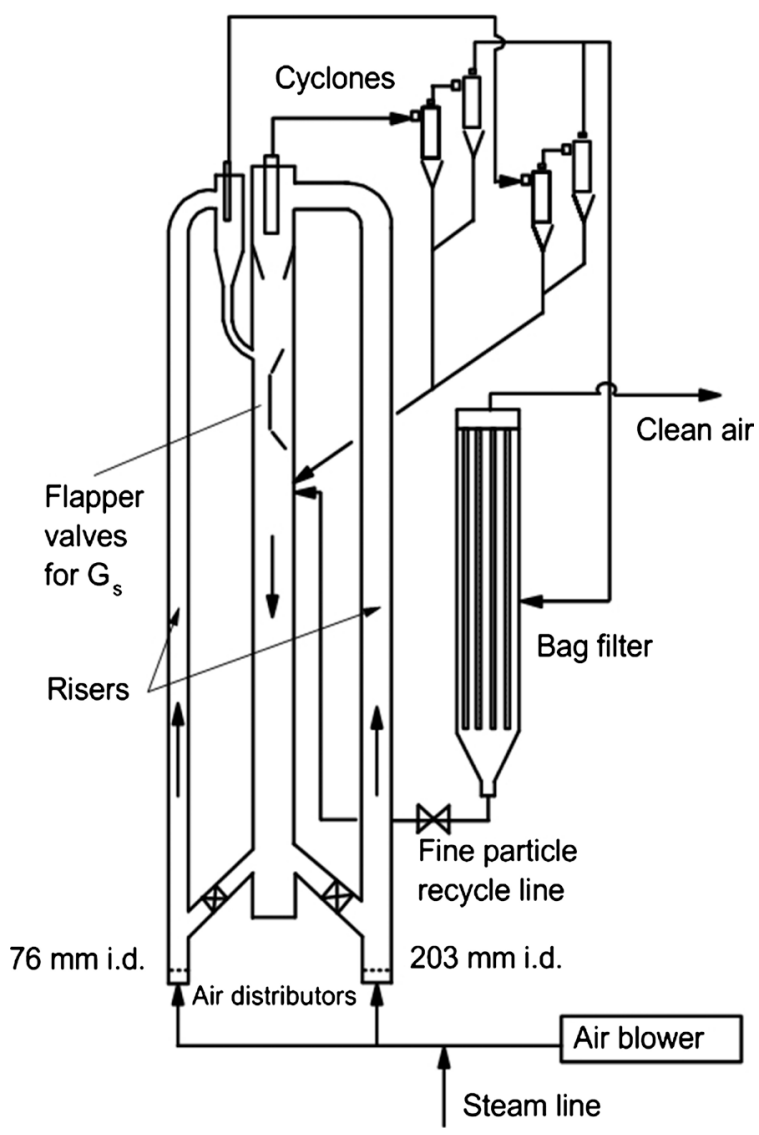

Figure 1. The circulating fluidized bed with two riser system. 
The mathematical formulations of the computed parameters are presented in Table 1.

Where $\varepsilon_{s}$ is the solid concentration signal from $i=1,2,3, \cdots, N$ data; $\sigma\left(\varepsilon_{s}\right)_{\max }$ and $\varepsilon_{s, m f}$ are the maximum possible standard deviation for a particular cross-sectional average solids concentration and the local solids concentration at minimum fluidization respectively.

\section{Results and Discussion}

\subsection{The Local Mean Solid Concentration}

This study employed the mean $\left(\overline{\varepsilon_{s}}\right)$ to evaluate the radial distribution of local average solid concentration along the riser height. The radial profiles of the local mean solid concentration at different axial levels of the riser for different operating conditions are shown in Figure 2. The figure shows uniform and flat profiles in the centre and the middle region of the reactor and then increases gradually with irregular and non-uniform profiles towards the wall. This observation suggests non distribution of solid concentration with dilute gas-solid suspension flow in the central region and dense gas-solid suspension flow towards the wall of the riser. The central region has relatively lower average solid concentration which then increases to relatively higher values towards the wall which suggest presence of core-annulus flow structure in the radial direction. In the entrance

Table 1. Mathematical formulations of various statistical parameters used in this study.

\begin{tabular}{|c|c|c|c|}
\hline Parameter & $\begin{array}{l}\text { Microscopicl } \\
\text { macroscopic }\end{array}$ & Formula & Reference \\
\hline Mean, $\overline{\varepsilon_{\mathrm{s}}}$ & Macroscopic & $\overline{\varepsilon_{s}}=\frac{1}{N} \sum_{i=1}^{N} \varepsilon_{s}(i)$ & $\begin{array}{l}{[1][7][8]} \\
{[12][16]}\end{array}$ \\
\hline Standard Deviation, $\sigma\left(\varepsilon_{s}\right)$ & Microscopic & $\sigma\left(\varepsilon_{s}\right)=\sqrt{\frac{1}{N-1} \sum_{i=1}^{N}\left(\varepsilon_{s}(i)-\overline{\varepsilon_{s}}\right)^{2}}$ & {$[8][22][23]$} \\
\hline Skewness, $S_{k}$ & Microscopic & $S_{k}=\frac{1}{N \sigma\left(\varepsilon_{s}\right)^{3}} \sum_{i=1}^{N}\left(\varepsilon_{s}(i)-\overline{\varepsilon_{s}}\right)^{3}$ & [7] [8] [23] \\
\hline Kurtosis, $K_{u}$ & Microscopic & $K_{u}=\frac{1}{N \sigma\left(\varepsilon_{S}\right)^{4}} \sum_{i=1}^{N}\left(\varepsilon_{S}(i)-\overline{\varepsilon_{S}}\right)^{4}$ & {$[8][23]$} \\
\hline Intermittent Index, $\gamma$ & Macroscopic & $\gamma=\frac{\sigma\left(\varepsilon_{s}\right)}{\sigma\left(\varepsilon_{s}\right)_{\max }}=\frac{\sigma\left(\varepsilon_{s}\right)}{\sqrt{\overline{\overline{\varepsilon_{s}}\left(1-\overline{\varepsilon_{s}}-\varepsilon_{s, m f}\right)}}}$ & [7] [22] \\
\hline $\begin{array}{l}\text { Average Absolute Deviation } \\
\qquad(A A D)\end{array}$ & Microscopic & $A A D=\frac{1}{N} \sum_{i=1}^{N}\left(\left|\varepsilon_{s}(i)-\overline{\varepsilon_{s}}\right|\right)$ & {$[18][23]$} \\
\hline $\begin{array}{l}\text { Radial Non-Uniformity Index } \\
\qquad(R N I)\end{array}$ & Macroscopic & $\operatorname{RNI}\left(\varepsilon_{\mathrm{s}}\right)=\frac{\sigma\left(\varepsilon_{s}\right)}{\sigma\left(\varepsilon_{\mathrm{s}}\right)_{\max }}=\frac{\sigma\left(\varepsilon_{\mathrm{s}}\right)}{\sqrt{\overline{\varepsilon_{s}}\left(\varepsilon_{s, m f}-\overline{\varepsilon_{s}}\right)}}$ & [16] [21] \\
\hline $\begin{array}{l}\text { Probability Density Function } \\
\text { (PDF) }\end{array}$ & Microscopic & $f(x)=\operatorname{Pr}\left[\varepsilon_{s}=x\right]$ & [1] [7] [12] \\
\hline Coefficient of Variation, $C V$ & Macroscopic & $C V=\frac{\sigma\left(\varepsilon_{s}\right)}{\overline{\varepsilon_{s}}}$ & {$[18][23]$} \\
\hline
\end{tabular}



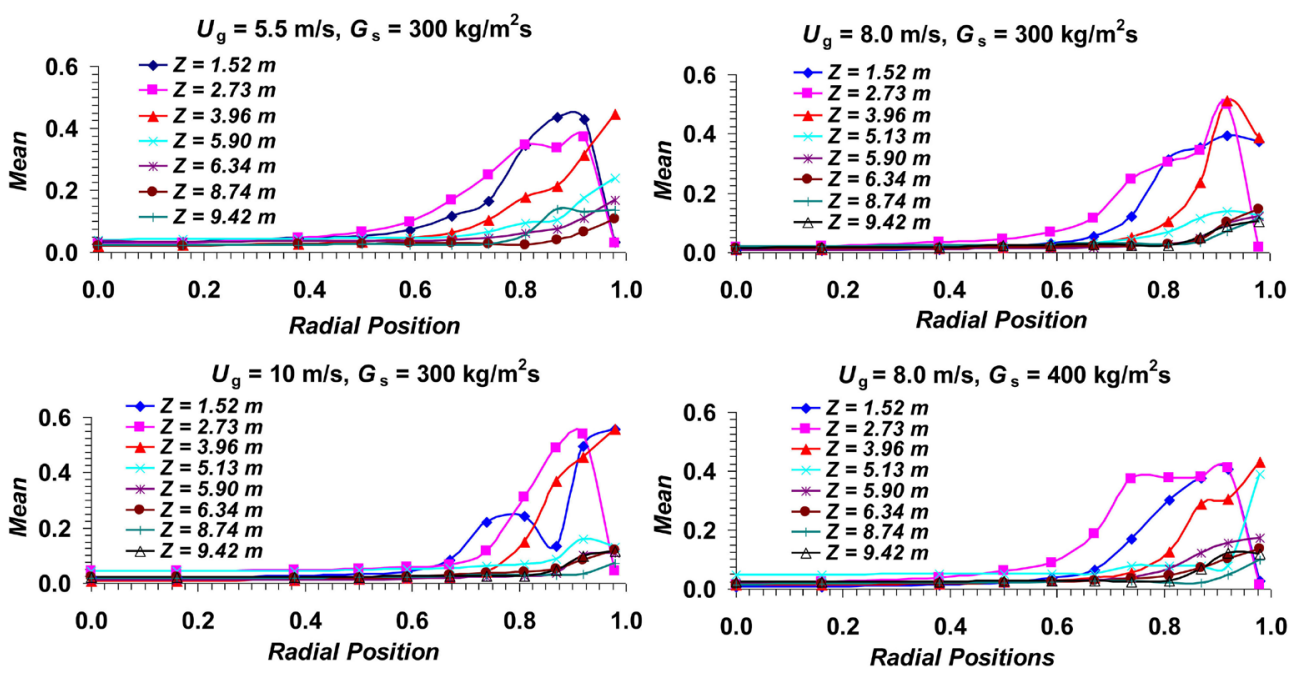

Figure 2. Radial profiles of the average solid concentration at different operating conditions.

and developing flow section $(Z \leq 3.96 \mathrm{~m})$ in the wall region, profiles are irregular with relatively higher solid concentration and then become regular with relatively lower values in the upper section at $Z>5.13 \mathrm{~m}$. This observation suggests relatively fluctuating flow structure with denser solid concentration compared to the fully developed flow section. Irregular profiles of solid concentration towards the wall reveals non-uniform flow structures in the wall region which might be attributed to the effects of non-uniform reintroduction of solid flux at the entrance and pulsation of gas from the air distributor. Such results concur with findings in other studies [1] [12] [16] [17].

However, one of the peculiar finding is the sudden drop in solid concentration close to the wall at $r / R=0.98$, especially at the level of $Z=2.73 \mathrm{~m}$ for all operating conditions as shown in Figure 2. For $U_{g}=8 \mathrm{~m} / \mathrm{s}$ and $G_{s}=300 \mathrm{~kg} / \mathrm{m}^{2} \mathrm{~s}$ the solid concentration increases to the maximum value of $\overline{\varepsilon_{s}}=0.499$ at $r / R=0.92$ and then drops to $\overline{\varepsilon_{\mathrm{s}}}=0.0162$ at $r / R=0.98$. When $U_{\mathrm{g}}=10 \mathrm{~m} / \mathrm{s}$ and $G_{s}=300$ $\mathrm{kg} / \mathrm{m}^{2} \mathrm{~s}$ the solid concentration reaches a maximum value of $\overline{\varepsilon_{\mathrm{s}}}=0.537$ at $r / R=$ 0.92 and then drops to $\overline{\varepsilon_{s}}=0.0418$ at $r / R=0.98$. Such observations are also found at $Z=1.52 \mathrm{~m}$ for $U_{\mathrm{g}}=5.5 \mathrm{~m} / \mathrm{s}$ and $G_{s}=300 \mathrm{~kg} / \mathrm{m}^{2} \mathrm{~s}$ where the solid concentration reaches a maximum of $\overline{\varepsilon_{\mathrm{s}}}=0.435$ at $r / R=0.87$ and then drops to $\overline{\varepsilon_{s}}=0.0333$ at $r / R=0.98$. This behaviour might be due to gas flow turbulences which lead to relatively high fluctuations between dilute and dense gas-solid suspensions flow.

\subsection{Standard Deviation of Solid Concentration Signals}

The standard deviation $\left(\sigma\left(\varepsilon_{s}\right)\right)$ was used to examine the solid concentration fluctuations from the mean values when the riser is operated at different operating conditions. Figure 3 shows the radial profiles of standard deviation of the solid concentration signals for various axial levels of the riser at various operating conditions. Profiles are flat in the centre region with low values of $\sigma\left(\varepsilon_{s}\right)$ and then increases in the middle region to relatively higher values towards the 

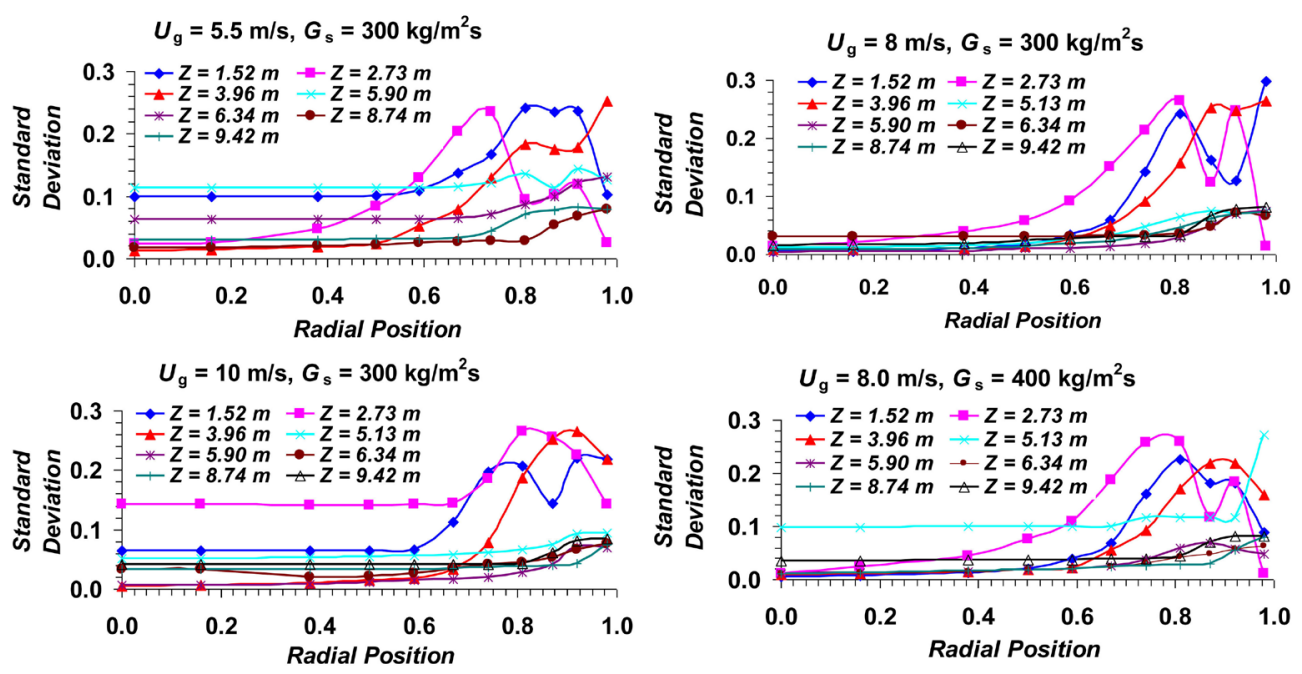

Figure 3. Radial profiles of the standard deviation of solid concentration signals at different operating conditions.

wall of the riser. This shows that the centre and the middle regions are dominated with low fluctuations in solid concentrations compared to the wall region. This suggests a relatively higher uniform gas-solid flow structure in the central region or core-region than in the annulus region which is mostly the wall region. Also profiles in the entrance and developing flow sections $(Z \leq 3.96 \mathrm{~m})$ are irregular with relatively higher $\sigma\left(\varepsilon_{s}\right)$ compared to the developed/upper sections of the riser. This shows high fluctuations of solid concentration in the entrance and developing flow sections compared to the top sections suggesting a non-uniform and highly fluctuating flow structures. Also profiles in the entrance and developing flow sections $(Z \leq 3.96 \mathrm{~m})$ increases gradually towards the wall to maximum values and then drops suddenly to lower values. For instance, at $Z=1.52$ $\mathrm{m}$, for $U_{g}=5.5 \mathrm{~m} / \mathrm{s}$ and $G_{s}=300 \mathrm{~kg} / \mathrm{m}^{2} \mathrm{~s}$, values of standard deviation increases to a maximum value of $\sigma\left(\varepsilon_{s}\right)=0.241$ at $r / R=0.81$ and then drops to $\sigma\left(\varepsilon_{s}\right)=0.102$ at $r / R=0.98$. Similar observation is seen at $Z=2.73 \mathrm{~m}$ where standard deviation increases to a maximum value of $\sigma\left(\varepsilon_{\mathrm{s}}\right)=0.265$ at $r / R=$ 0.81 and then drops to $\sigma\left(\varepsilon_{\mathrm{s}}\right)=0.142$ at $r / R=0.98$. The sudden drop in standard deviation suggests an abrupt decrease in fluctuations of the solid concentration in the gas-solid suspension flow. Similar observations are reported in other studies at $Z=1.94 \mathrm{~m}$ and $Z=5.84 \mathrm{~m}$ for the operating conditions of $U_{g}=7$ $\mathrm{m} / \mathrm{s}$ and $G_{s}=500 \mathrm{~kg} / \mathrm{m}^{2} \mathrm{~s}, U_{g}=9 \mathrm{~m} / \mathrm{s}$ and $G_{s}=500 \mathrm{~kg} / \mathrm{m}^{2} \mathrm{~s}$ and $U_{g}=9 \mathrm{~m} / \mathrm{s}$ and $G_{s}$ $=1000 \mathrm{~kg} / \mathrm{m}^{2} \mathrm{~s}$ [16]. Further, for $U_{g}=8 \mathrm{~m} / \mathrm{s}$ and $G_{s}=300 \mathrm{~kg} / \mathrm{m}^{2} \mathrm{~s}$ profiles at the central region of the riser are closest to each other with relatively lower values of standard deviations. This might be due to relatively lower axial variations in the gas-solid fluctuations indicating a relatively uniform gas-solid suspension flow in the axial direction towards the top of the riser.

\subsection{Skewness $\left(S_{k}\right)$}

Results in Figure 4 present the radial profiles of Skewness in various axial levels 

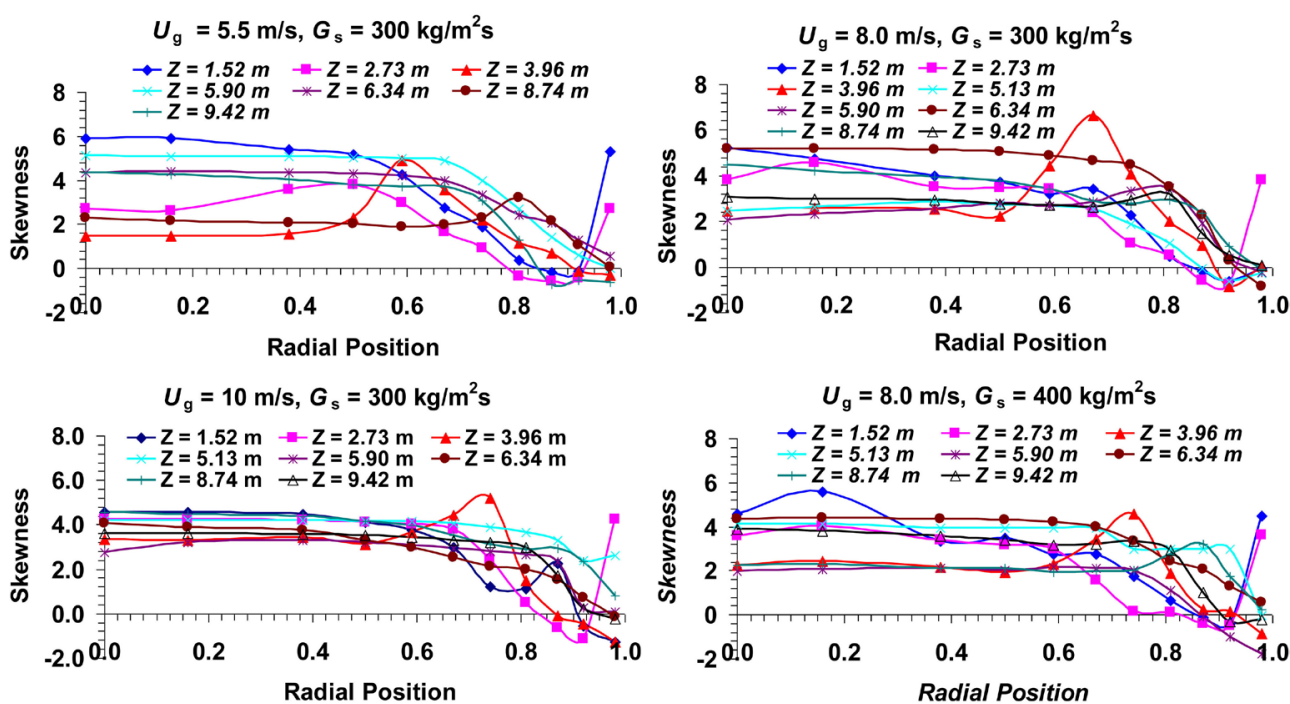

Figure 4. Radial profiles of the skewness at different operating conditions.

of the riser. Skewness profiles are relatively flat with relatively higher positive values in the centre and middle region which then decreases gradually towards the wall. However, some profiles in the entrance section, that is profiles at $Z=$ 1.52 and $2.73 \mathrm{~m}$ decreases gradually in the wall region to negative values and then increases sharply to relatively higher positive values close to the wall. For instance when $U_{g}=5.5 \mathrm{~m} / \mathrm{s}$ and $G_{s}=300 \mathrm{~kg} / \mathrm{m}^{2}$ s the Skewness values decreases to $S_{k}=-0.193$ at $r / R=0.87$ and then increases sharply to $S_{k}=5.32$ at $r / R=0.87$. Also when $U_{g}=10 \mathrm{~m} / \mathrm{s}$ and $G_{s}=300 \mathrm{~kg} / \mathrm{m}^{2}$ s the Skewness values decreases to $S_{k}$ $=-1.15$ at $r / R=0.92$ and then increases sharply to $S_{k}=4.24$ at $r / R=0.98$. These results indicate that solid concentration data signals in the wall region are non-symmetrical with positive or right skewed distribution which forms PDF with longer tails towards the right. This suggests that dense suspension flow dominates in the wall region of the riser.

\subsection{Kurtosis $\left(K_{u}\right)$}

In this study Kurtosis $\left(K_{u}\right)$ was used to examine the nature of the solid concentration signal distribution, whether peaked or flat PDF distribution. Figure 5 shows Kurtosis profiles of the solid concentration for various operating conditions. Kurtosis profiles are generally flat in the centre and middle region with relatively higher positive values and then decrease gradually towards the wall. However, in the entrance section at $Z=1.52 \mathrm{~m}$ and $2.73 \mathrm{~m}$ Kurtosis values decreases gradually in the wall region to minimum values and then close to the wall at $r / R=0.98$ increase to higher values corresponding to their respective values in the centre and middle regions. For instance, when $U_{g}=5.5 \mathrm{~m} / \mathrm{s}$ and $G_{s}$ $=300 \mathrm{~kg} / \mathrm{m}^{2}$ s profiles at $Z=1.52 \mathrm{~m}$ decrease to the minimum values of $K_{u}=$ -1.58 at $r / R=0.87$ and then increases to $K_{u}=28.5$ at $r / R=0.98$. When the velocity, $U_{g}=8 \mathrm{~m} / \mathrm{s}$ and $G_{s}=300 \mathrm{~kg} / \mathrm{m}^{2} \mathrm{~s}$, profiles at $Z=1.52$ and $Z=2.73 \mathrm{~m}$ decrease to minimum values of $K_{u}=-0.943$ at $r / R=0.81$ and $K_{u}=-0.773$ at $r / R=$ 
0.92 respectively and then increase to $K_{u}=19.9$ and 23 respectively at the wall ( $r / R=0.98)$. These observations indicates that the solid concentration data signals form a relatively flat and right skewed PDF in the wall region while at the wall, PDF profiles become peaked with short tails towards the right. This suggests that close to the wall $(r / R=0.98)$ there might be a slight uniformity due to formation of dense suspension or heavy clusters of solid particles.

\subsection{Intermittent Index $(\gamma)$}

This study employed Intermittent Index factor to examine both solid flow fluctuations and the extent of segregation in the gas-solid flow suspension; whereby higher values indicate segregated gas-solid flow behaviour and lower values show a more uniform gas-solid suspension. Figure 6 shows the radial profiles of the Intermittent Index for various operating conditions. The Intermittent Index
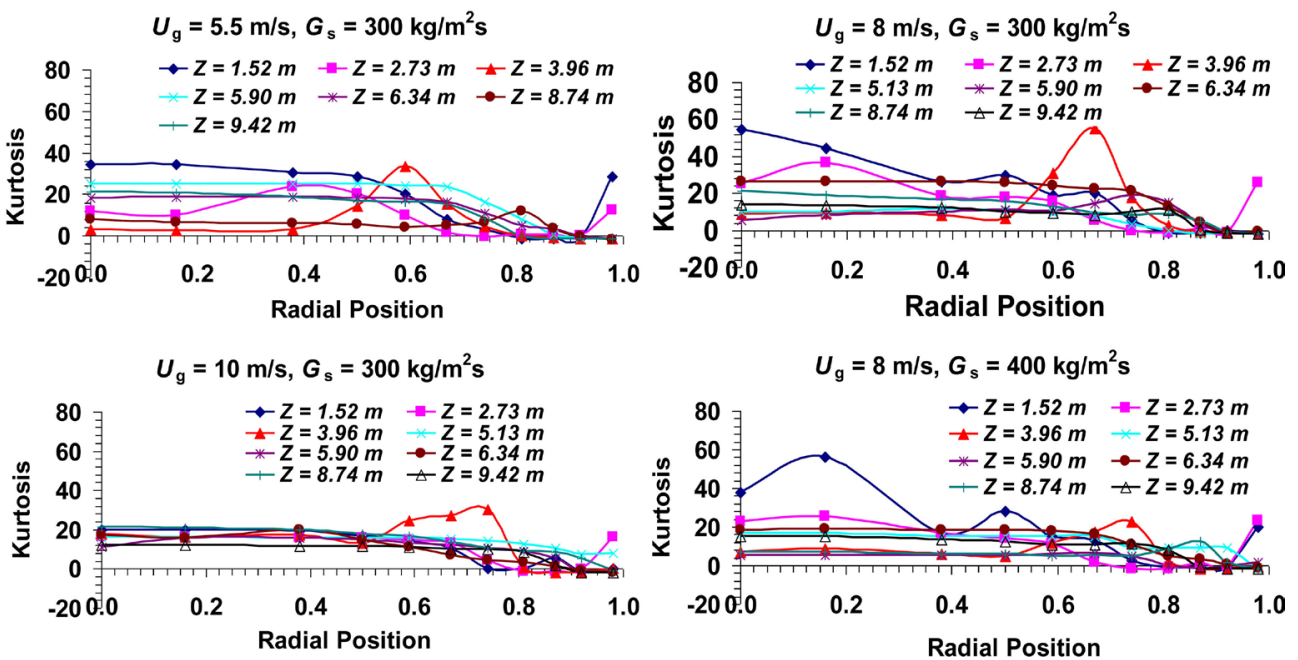

Figure 5. The radial profiles of Kurtosis at different operating conditions.
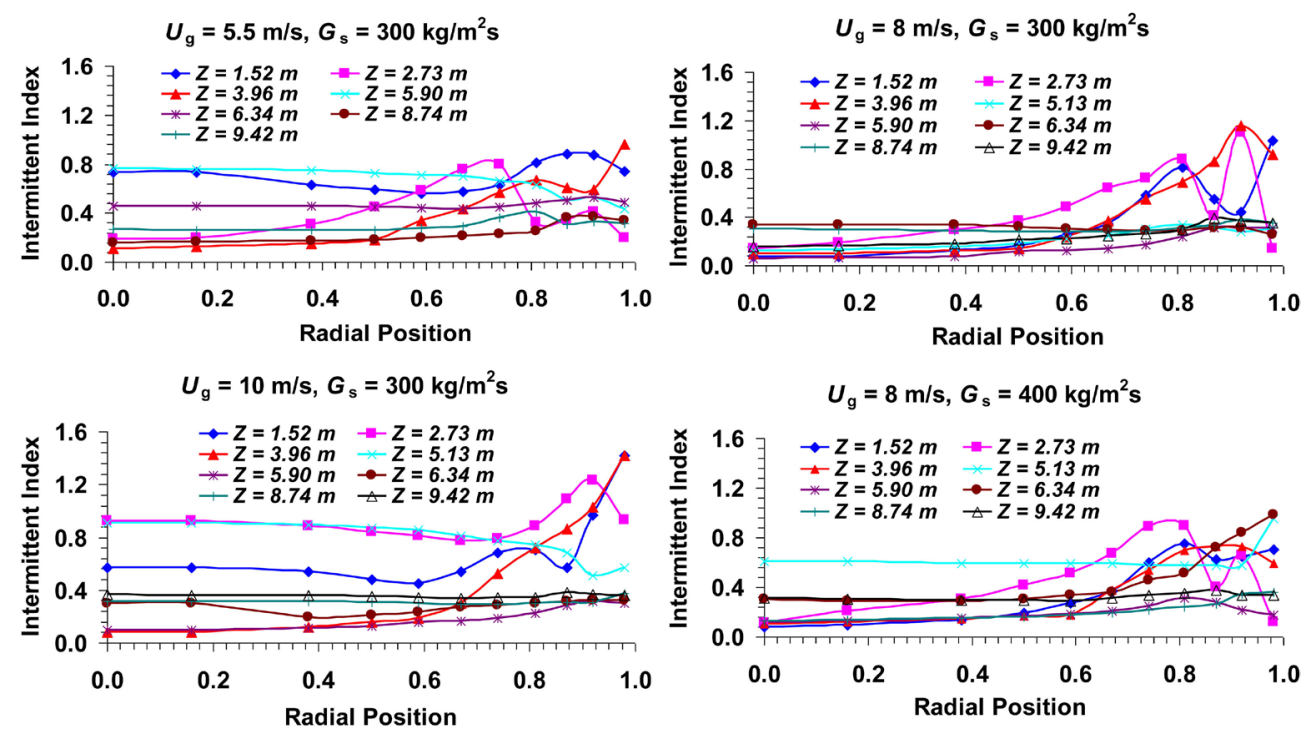

Figure 6. The radial profiles of Intermittent Index at different operating conditions. 
profiles are flat and regular with slightly lower values in the centre and then becomes irregular and slightly increasing in the wall region especially in the entrance section for $Z=1.52$ and $2.73 \mathrm{~m}$. The relative increases of the Intermittent Index values in the wall region especially in the entrance and developing flow section $(Z \leq 3.96 \mathrm{~m})$ shows slight segregated flow behaviour in these sections. This might be due to non-uniform reintroduction of solid and pulsation of the gas from the distributor which results in a more segregated flow. However, in the developed flow zone, i.e. $Z=6.23 \mathrm{~m}$, values of $\gamma$ are relatively lower with regular and slightly flat profiles which suggests a slightly uniform gas-solid suspension flow. Further, it can be observed that when $U_{g}=8 \mathrm{~m} / \mathrm{s}$ and $G_{s}=300$ $\mathrm{kg} / \mathrm{m}^{2}$ s profiles are very close to each other compared to profiles in other process conditions. This might suggests a less segregated and non-fluctuating gas-solid flow which is more likely to occur for the dilute gas-solid flow in the central region of the riser.

\subsection{Average Absolute Deviation $(A A D)$}

The $A A D$ was employed to examine the average value of the departure of instantaneous data values of solid concentration from the mean value. Figure 7 shows the radial profiles of the average absolute deviation at different operating conditions. The $A A D$ profiles are relatively flat and constant in the centre and middle regions and then gradually become irregular and fluctuating with some increasing and some decreasing. Such behaviour are observed for some profiles, for instance at $Z=1.52,2.73,3.96$ and $5.90 \mathrm{~m}$. The $A A D$ profiles reveal relatively uniform flow or less fluctuating flow in the centre and middle region of the riser while the gas-solid flow in the wall region is relatively non-uniform and fluctuating especially in the entrance and developing flow sections. Further, the effects of processing condition can be observed when the gas velocity increases which results in higher $A A D$. For instance, when $U_{g}=10 \mathrm{~m} / \mathrm{s}$ and $G_{s}=300 \mathrm{~kg} / \mathrm{m}^{2} \mathrm{~s}$,
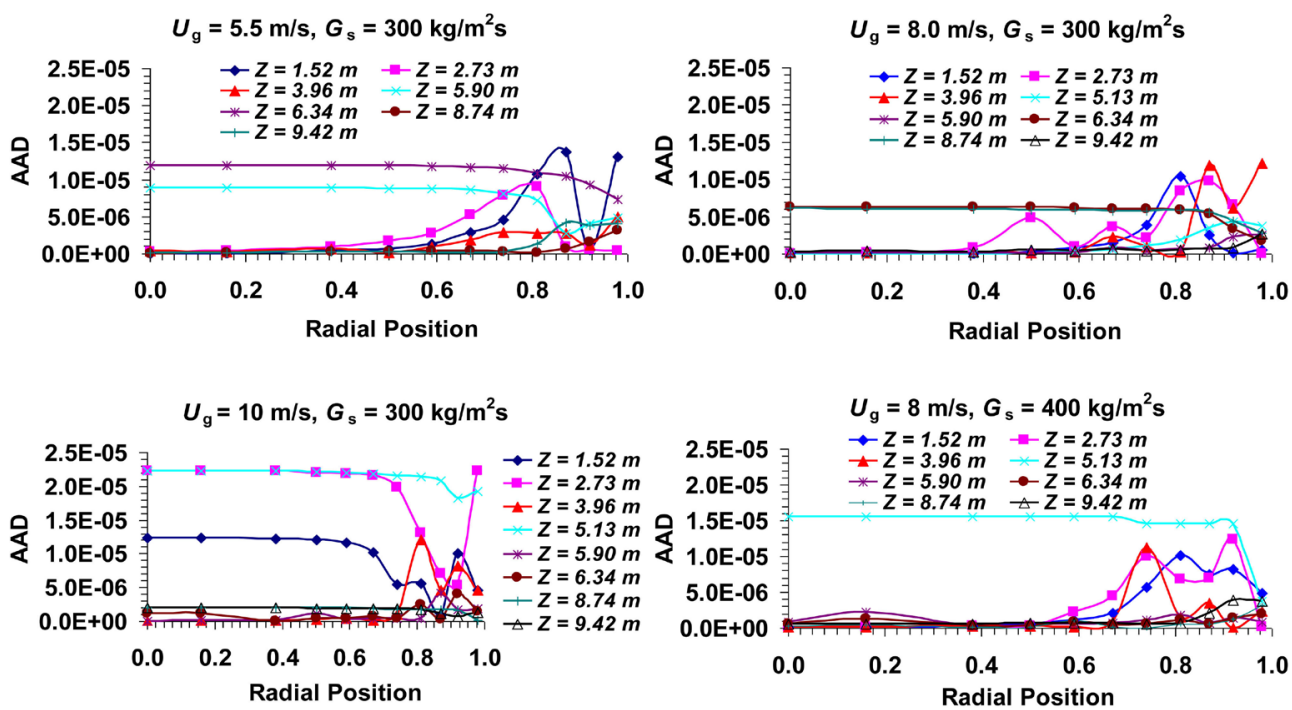

Figure 7. The radial profiles of the average absolute deviations at different operating conditions. 
$A A D$ profiles becomes wider spread in the central region which span to the maximum values of $A A D=2.22 \times 10^{-5}$ for $Z=2.73$ and $5.13 \mathrm{~m}$. This shows higher average departure of the solid concentration data values from the mean. Such observation suggests presence of differences in the flow structures between the entrance and the transition zone with notable relative fluctuations between the less dilute and most dilute suspensions in the respective sections.

\subsection{Coefficient of Variation ( $\mathrm{CV}$ )}

The coefficient of variation was used to measure the relative variability or the level of fluctuations of the gas-solid concentration distribution in the riser. Figure 8 shows the profiles of the coefficient of variation at different operating conditions. Profiles are relatively flat and slightly regular in the centre and middle regions and then become irregular and fluctuating towards the wall. Most of the profiles decrease gradually towards the wall. Such profiles includes those at $Z=$ $6.34 \mathrm{~m}$ for $U_{g}=8.0 \mathrm{~m} / \mathrm{s}$ and $G_{s}=300 \mathrm{~kg} / \mathrm{m}^{2} \mathrm{~s}, Z=1.52 \mathrm{~m}$ for $U_{g}=10 \mathrm{~m} / \mathrm{s}$ and $G_{s}$ $=300 \mathrm{~kg} / \mathrm{m}^{2} \mathrm{~s}$ and $Z=5.90$ for $U_{g}=5.5 \mathrm{~m} / \mathrm{s}$ and $G_{s}=300 \mathrm{~kg} / \mathrm{m}^{2} \mathrm{~s}$. The decreasing trend suggests that the variation of solid concentration in the gas-solid suspension flow decreases towards the wall which might be due to the increase in concentration from dilute to dense suspension flow.

However some of the profiles decreases progressively and then increase sharply close to the wall $(r / R=0.98)$. Such tendency is shown by the profiles at $Z$ $=1.52 \mathrm{~m}$ when $U_{g}=8 \mathrm{~m} / \mathrm{s}$ and $G_{s}=300 \mathrm{~kg} / \mathrm{m}^{2} \mathrm{~s}$ where the $C V$ decreases to a minimum value of $C V=0.448$ and then increases to $C V=3.15$. Also the same tendency is shown by the same profile when $U_{g}=5.5 \mathrm{~m} / \mathrm{s}$ and $G_{s}=300 \mathrm{~kg} / \mathrm{m}^{2} \mathrm{~s}$ where the profile decreases to $C V=0.554$ and then increases to $C V=3.07$. Further, this behaviour is also shown at $Z=2.73 \mathrm{~m}$ when $U_{g}=10 \mathrm{~m} / \mathrm{s}$ and $G_{s}=300$
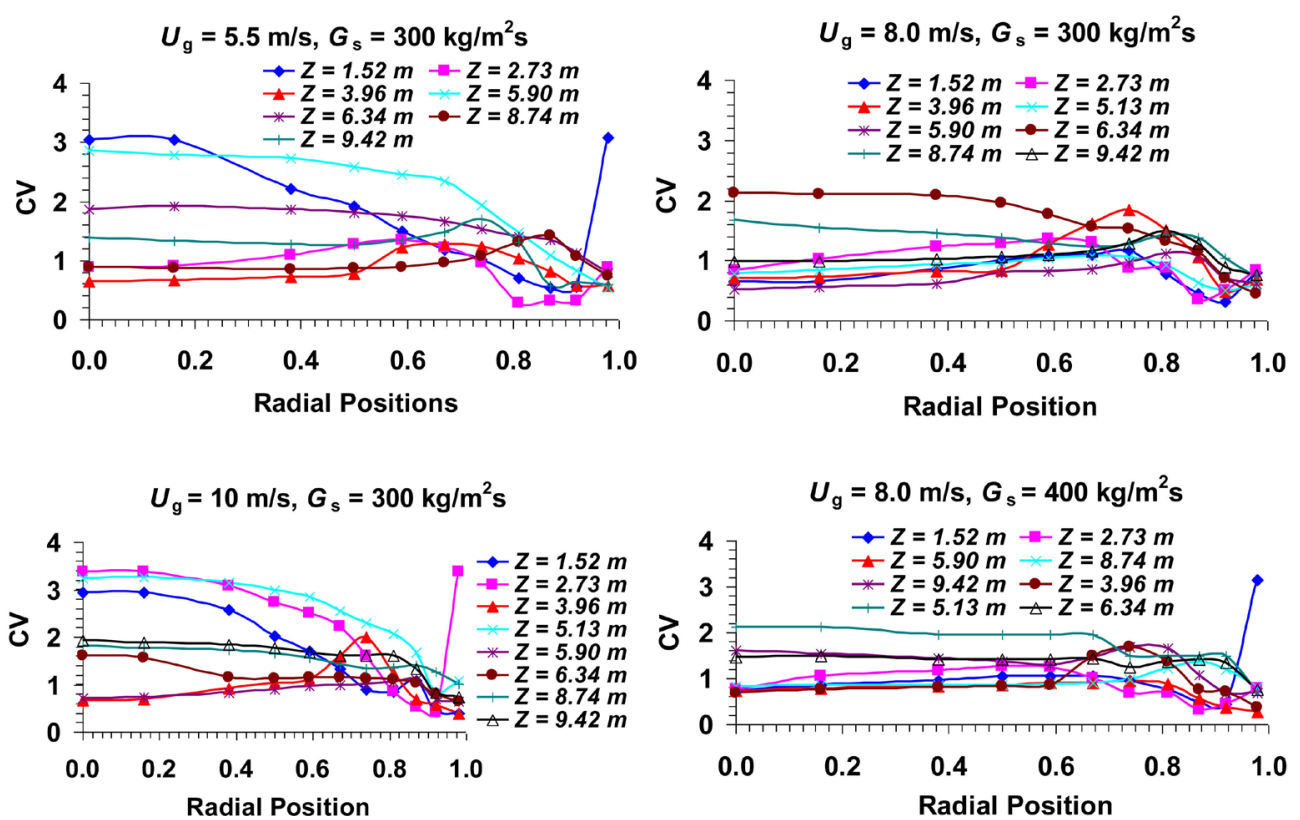

Figure 8. The radial profiles of the coefficient of variations at different operating conditions. 
$\mathrm{kg} / \mathrm{m}^{2} \mathrm{~s}$ where the coefficient of variation decreases to $C V=0.421$ and then increases to $C V=3.39$. Higher values of $C V$ occurs when the suspension flow has high variation in solid concentration leading to high standard deviation relative to its mean or in dilute suspension where the mean solid concentration is very low compared to its variations or fluctuations expressed in standard deviation. In this case higher values in the centre and middle region may suggests presence of low local mean solid concentration which is as shown in Figure 2. Towards the wall the observed decreases in $C V$ might be due to the increase in local mean solid concentration leading to dense suspension flow.

\subsection{Radial Non-Uniformity Index (RNI)}

The gas-solid flow non-uniformities in the riser were assessed using the Radial Non-uniformity Index $(R N I)$. Figure 9 presents the profiles of $R N I$ of the solid concentration along the axial direction. From the figure it is observed that values of $R N I$ are high in the entrance and developing flow sections, in the levels of $Z \leq$ $3.96 \mathrm{~m}$ and then decreases sharply in the transition section to attain slightly decreasing profiles at $Z \geq 5.90 \mathrm{~m}$ along the axial direction in the fully developed section. Higher $R N I$ in the entrance section suggests presence of higher flow non-uniformities compared to the top sections of the riser in the fully developed flow section. This may be attributed to the flow development of the solids in the higher solid concentration zone which brings about higher solid fluctuations in the bottom section. In the fully developed flow section at $Z \geq 5.90 \mathrm{~m} R N I$ values becomes lower and slightly decreasing due to less non-uniformity which suggests relatively uniform gas-solid suspension flow. However, at the top, $Z=9.42$ m the profiles shows an increase in $R N I$ values which might be due to solid backflow induced by the exit effect. Also profiles show that in the entrance section, $Z \leq 3.96 \mathrm{~m}$, the $R N I$ increases with increase in velocity at constant solid flux. This can be due to the increase in solid particle interactions and disorders when the superficial gas velocity is increased. In the fully developed flow section values of the $R N I$ are relatively lower at higher gas velocity when compared with values at lower gas velocity.

\subsection{Probability Density Function (PDF)}

The PDF was used to examine the nature of solid distribution in the gas-solid

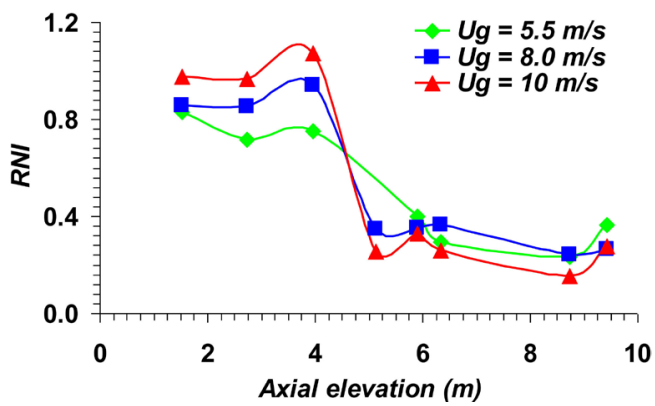

Figure 9. The axial profiles of $R N I$ at different superficial gas velocity and $G_{S}=300 \mathrm{~kg} / \mathrm{m}^{2} \mathrm{~s}$. 
suspension in the wall region, from the entrance section to the top section in comparison to the centre region. Figure 10 shows the PDF of the solid concentration at $U_{g}=5.5,8$ and $10 \mathrm{~m} / \mathrm{s}$ and $G_{s}=300 \mathrm{~kg} / \mathrm{m}^{2} \mathrm{~s}$. For each operating condition, the shapes of PDF at the centre region $(r / R=0.0)$ are tall in the left for low solid concentration with long tails towards the right (positively skewed) for all axial elevations. This shows a highly dilute gas-solid suspension flow with slight fluctuations of the less dilute to dilute solid concentrations. In the wall region especially for $r / R \geq 0.8$ shapes of PDF in the entrance section, developing flow and the transition sections $(Z \leq 5.90 \mathrm{~m})$ differs from that in the fully developed section. In the entrance and developing flow sections, profiles are either tall at the left with long tail towards higher solid concentration, i.e. positively skewed distribution; or single peaked with tails both sides; or double peaked profiles. But

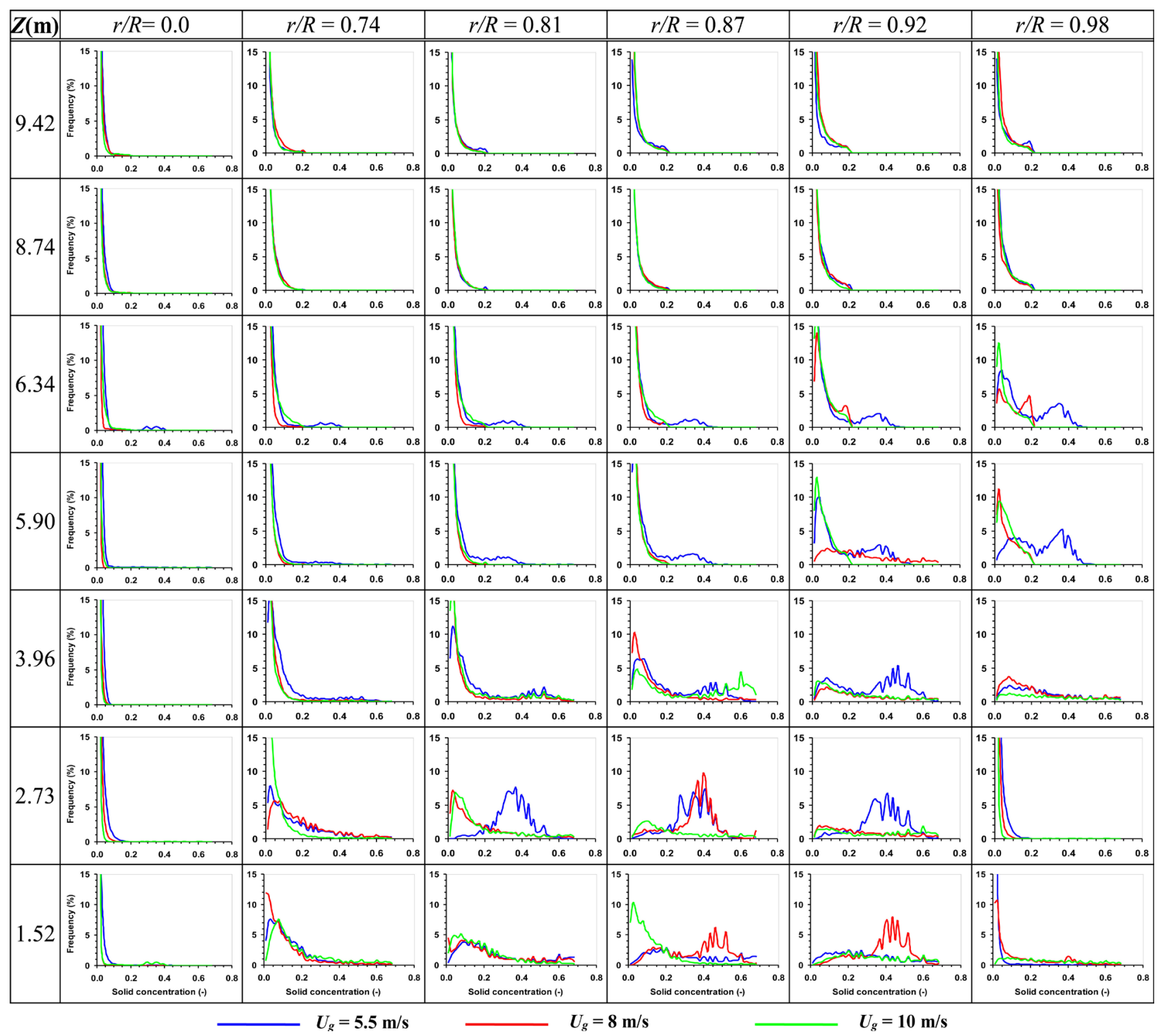

Figure 10. Probability density function (PDF) profiles of the solid concentration time series at different velocities and spatial locations in the riser at $G_{s}=300 \mathrm{~kg} / \mathrm{m}^{2}$ s. 
in the fully developed section $Z>5.90 \mathrm{~m}$ PDF are tall in the left with long tail in the right towards higher solid concentration. These observations show that in the entrance and developing flow sections there are high flow non-uniformities as compared to the fully developed section. Profiles in the centre region along the axial direction have no significant differences in shapes showing the increase in velocity have no significant influence on solid distribution in the core region. In the wall region, profiles show differences by having single and double peaks which shows coexistence of both dilute and dense phases.

When the gas velocity, $U_{g}=5.5 \mathrm{~m} / \mathrm{s}$ and solid flux, $G_{s}=300 \mathrm{~kg} / \mathrm{m}^{2} \mathrm{~s}$, PDF profiles in the entrance, developing flow and the transition sections are dominated by fluctuations in the wall region with higher solid concentration and right skewed profiles. Towards the wall $(0.87 \leq r / R \leq 0.98)$, in the levels from $3.96 \mathrm{~m} \leq$ $Z \leq 6.43 \mathrm{~m}$, PDF profiles are double peaked with tails towards the right. Such observation suggests coexistence of a dilute and dense phase. In the fully developed section, $Z \geq 6.43 \mathrm{~m}$, PDF profiles are tall on the left with longer and flat tail towards the right. This indicates that in the fully developed section is dominated with relatively dilute uniform flow.

When the operating condition is $U_{g}=8.0 \mathrm{~m} / \mathrm{s}$ and $G_{s}=300 \mathrm{~kg} / \mathrm{m}^{2} \mathrm{~s}$, PDF profiles in the wall region shows high non-uniformities in the entrance and developing flow sections. At $Z \leq 2.73 \mathrm{~m}$ the wall region is dominated by single and double peaks PDF with long tail to the right, in the higher concentration direction. This indicates high solid fluctuations with a highly segregated flow structures with coexistence of dilute and dense phase flow. In the transition section PDF are tall in the left and skewed to the right as seen at $3.96 \mathrm{~m}<Z \leq 6.34 \mathrm{~m}$ for $r / R=0.87$ and 0.98 . This indicates that the suspension flow is dominated with low solid concentration fluctuating with less dense phases. In the fully developed section the flow is relatively uniform and dominated with very dilute suspension.

For $U_{g}=10 \mathrm{~m} / \mathrm{s}$ and $G_{s}=300 \mathrm{~kg} / \mathrm{m}^{2} \mathrm{~s}$ the PDF profiles in the centre region are tall in the left with long tail towards high solid concentration, that is, positively skewed profiles. This show the centre region is dominated by the dilute gas-solid suspension flow. PDF profiles in the wall region of the entrance section are positively skewed towards high concentration which shows fluctuations between dilute and dense suspensions. Such profiles are found at $1.52 \leq Z \leq 6.34 \mathrm{~m}$ in the wall region for $0.74 \leq r l R \leq 0.98$. However, from the transition section towards the exits, i.e. at $Z \geq 5.13 \mathrm{~m}$ and $r / R=0.74$ and 0.87 ; PDF are positively skewed with left peak and long tails towards the high concentration direction. Such PDF are also found from $Z=8.74 \mathrm{~m}$ to $Z=9.42 \mathrm{~m}$ at $r / R=0.92$ and 0.98 . Likewise the same PDF shapes are found in the centre region. This suggests presence of uniform low solid concentration suspension flow.

\subsection{Analysis of Probability Density Function Profiles}

Further observation of the shapes of the PDF reveals four different types, i.e. A, $\mathrm{B}, \mathrm{C}$ and $\mathrm{D}$ as summarised in Table 2. 
Table 2. Types of PDF obtained in the PDF analysis at different operating conditions.

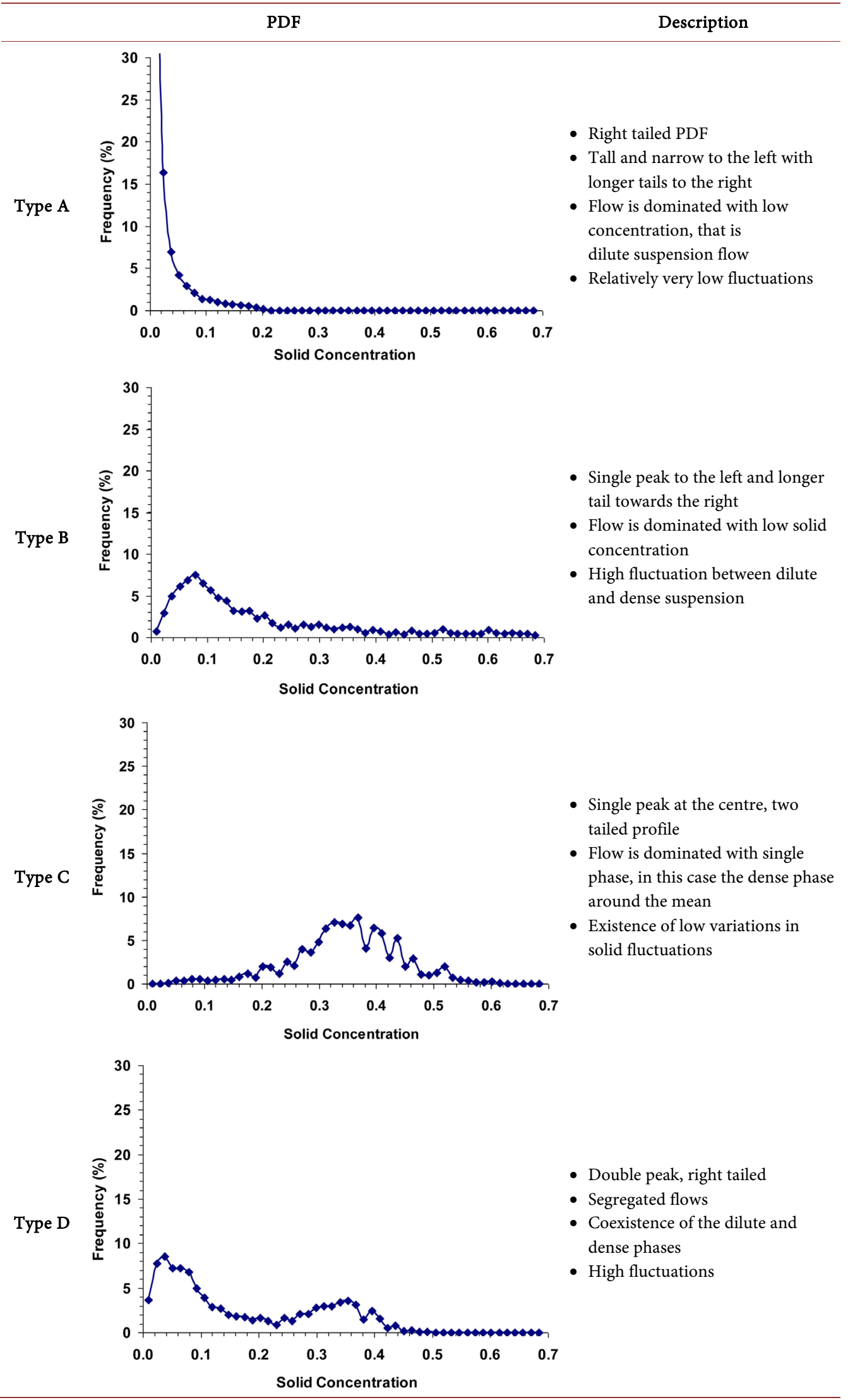


Type A: PDF profiles are tall at the left with longer tail to the right. These PDF are found mostly in the centre and the middle region of the riser from the bottom to the top section. Also they are found in the wall region of the fully developed section at $Z \geq 8.74 \mathrm{~m}$. this shows the gas-solid flow is dominated with a dilute or very low solid concentration.

Type B: PDF profiles are single peaked at the left with a longer tail to the right. These profiles are found in the entrance, developing flow and transition sections when $U_{g}=5.5,8.0$ and $10 \mathrm{~m} / \mathrm{s}$ and $G_{s}=300 \mathrm{~kg} / \mathrm{m}^{2} \mathrm{~s}$ as shown in Figure 10. Also such profile are found in the fully developed sections at $Z=6.34$ and $9.42 \mathrm{~m}$ as shown in Figure 10. These profiles suggest that suspension flow is dominated with low solid concentration.

Type C: PDF profiles are single peaked at the centre with tails on both sides. These type of profiles are found in the wall region at $r / R=0.87$ and $Z=2.73$ when the operating condition is $U_{g}=8 \mathrm{~m} / \mathrm{s}$ and $G_{s}=300 \mathrm{~kg} / \mathrm{m}^{2} \mathrm{~s}$. But also they are found at $r / R=0.81,0.87$ and 0.92 at $Z=2.73 \mathrm{~m}$ when $U_{g}=5.5 \mathrm{~m} / \mathrm{s}$ and $G_{s}=$ $300 \mathrm{~kg} / \mathrm{m}^{2} \mathrm{~s}$ as shown in Figure 10. This observation suggests that gas-solid suspension flow is dominated by single phase, i.e. dense phase with relatively low variations in solid concentration.

Type D: PDF profiles are double peaked. Such profiles are found in the wall region at $r / R=0.87$ and $\mathrm{Z}=1.52 \mathrm{~m}$ as shown in Figure 10 when $U_{g}=8.0 \mathrm{~m} / \mathrm{s}$ and $G_{s}=300 \mathrm{~kg} / \mathrm{m}^{2}$ s. They are also found in the wall region from $\mathrm{Z}=3.96$ to $6.43 \mathrm{~m}$ when the operating condition is $U_{g}=5.5 \mathrm{~m} / \mathrm{s}$ and $G_{s}=300 \mathrm{~kg} / \mathrm{m}^{2} \mathrm{~s}$ as shown in Figure 10. The double peaked PDF profiles show the existence of segregated flows i.e. the existence of the dilute and dense phase in the gas-solid suspension. Such flow behaviour is mostly found in the entrance and developing flow sections along the wall region.

The summary of the spatial locations of various types of the PDF obtained in the analysis are shown in Table 3. Further, the summary of the study findings showing characteristics of various microscopic and macroscopic parameters are summarized in Table 4.

\section{Conclusions}

From this study the following conclusions can be made:

- The gas-solid suspension flow in the riser is dominated by low solid concentration at the centre and high solid concentration in the wall region forming a core-annulus flow structure.

- The mean solid concentration in the wall region decreases with riser height from the dense bottom section to less dense in the fully developed flow section.

- The gas-solid suspension flow in the centre region is dominated with dilute uniform flow while the wall region is dominated with high fluctuations in solid concentration.

- The bottom and developing flow sections of the riser exhibit high flow non-uniformities than the fully developed flow section of the riser. 
Table 3. Riser spatial locations at which different types of PDF are found.

\begin{tabular}{|c|c|c|c|c|}
\hline \multirow{2}{*}{$\begin{array}{l}\text { Operating } \\
\text { Condition }\end{array}$} & \multicolumn{4}{|c|}{ Location } \\
\hline & Type A & Type B & Type C & Type D \\
\hline $\begin{array}{c}U_{g}=5.5 \mathrm{~m} / \mathrm{s} \\
G_{s}=300 \\
\mathrm{~kg} / \mathrm{m}^{2} \mathrm{~s}\end{array}$ & $\begin{array}{l}\text { - At the centre region }(r / R=0.0) \\
\text { - At } r l R=0.74 \text { from } Z=5.90 \text { to } 9.42 \mathrm{~m} \\
\text { - At } r l R=0.81 \text { from } Z=6.43 \text { to } 9.42 \mathrm{~m} \\
\text { - At } r / R=0.92 \text {, from } Z=8.74 \text { to } 9.42 \mathrm{~m} \\
\text { - At } r l R=0.98 \text {, at } Z=9.42 \mathrm{~m}\end{array}$ & $\begin{array}{l}\text { - At } r / R=0.74 \text { from } Z=1.52 \text { to } 3.96 \mathrm{~m} \\
\text { - At } r / R=0.74 \text { from } Z=1.52 \text { to } 3.96 \mathrm{~m} \\
\text { - At } r / R=0.81 Z=1.52 \mathrm{~m} \text { and } Z=3.96 \mathrm{~m}\end{array}$ & $\begin{array}{l}- \text { At } Z=2.73 \text { from } r / R \\
=0.81 \text { to } 0.92\end{array}$ & $\begin{array}{l}\text { - At } r / R=0.87, Z= \\
3.96 \mathrm{~m} \\
\text { - At } r / R=0.92 \text { from } Z \\
=3.96 \text { to } 6.43 \mathrm{~m} \\
\text { - At } r / R=0.98, \text { from } Z \\
\quad=5.90 \text { to } 6.43 \mathrm{~m}\end{array}$ \\
\hline $\begin{array}{c}U_{g}=8.0 \mathrm{~m} / \mathrm{s} \\
G_{s}=300 \\
\mathrm{~kg} / \mathrm{m}^{2} \mathrm{~s}\end{array}$ & $\begin{array}{l}\text { - At } r / R=0.0 \text { from } Z=1.52 \text { to } 9.42 \mathrm{~m} \\
\text { - At } r / R=0.74 \text { and } r / R=0.81 \text { from } Z=3.96 \text { to } \\
9.42 \mathrm{~m} \\
\text { - At } r / R=0.87 \text { from } Z=5.90 \text { to } Z=9.48 \mathrm{~m} \\
\text { - At } r / R=0.92 \text { and } r / R=0.98 \text { from } Z=8.72 \text { to } \\
9.42 \mathrm{~m}\end{array}$ & $\begin{array}{l}\text { - At } r / R=0.74 \text { from } Z=1.52 \text { and } 2.73 \mathrm{~m} \\
\text { - } r / R=0.81 \text { from } Z=1.52 \text { to } Z=513 \mathrm{~m} \\
\text { - At } r / R=0.87, Z=3.96 \text { and } 5.13 \mathrm{~m} \\
\text { - } r / R=0.92 \text {, from } Z=2.73 \text { to } 6.34 \mathrm{~m} \\
\text { - At } r / R=0.98, Z=1.52,3.96 \text { to } 6.34 \mathrm{~m}\end{array}$ & $\begin{array}{l}\text { - At } r / R=0.87, Z= \\
2.73 \mathrm{~m} \\
\text { - At } r / R=0.92, Z= \\
2.73\end{array}$ & $\begin{array}{l}\text { - At } r / R=0.87, Z= \\
0.87 \mathrm{~m}\end{array}$ \\
\hline $\begin{array}{c}U_{g}=10 \mathrm{~m} / \mathrm{s} \\
G_{s}=300 \\
\mathrm{~kg} / \mathrm{m}^{2} \mathrm{~s}\end{array}$ & $\begin{array}{l}\text { - At } r / R=0.0 \text { form } Z=1.52 \text { to } 9.42 \mathrm{~m} \\
\text { - } r / R=0.74 \text { from } Z=3.96 \text { to } 9.42 \mathrm{~m} \\
\text { - } r / R=0.81 \text { from } Z=5.13 \text { to } 9.42 \mathrm{~m} \\
\text { - } r / R=0.87, Z=5.13 \text { to } 9.42 \mathrm{~m} \\
\text { - found from } r / R=0.92 \text { to } 0.98 \text { at } Z=8.74 \text { to } 9.42 \\
\quad \mathrm{~m}\end{array}$ & $\begin{array}{l}\text { - At } Z=1.52 \mathrm{~m}, r / R=0.74 \text { to } 0.87 \mathrm{~m} \\
\text { - At } Z=2.73, r / R=0.81 \text { to } 0.92 \mathrm{~m} \\
\text { - } r / R=0.81 \text { to } 0.92 \text { from } Z=1.52 \text { to } 3.96 \mathrm{~m} \\
\text { - } r / R=0.92 \text { to } 0.98 \text { at } Z=5.13 \text { to } Z=6.34 \mathrm{~m}\end{array}$ & - & - \\
\hline $\begin{array}{c}U_{g}=8.0 \mathrm{~m} / \mathrm{s} \\
G_{s}=400 \\
\mathrm{~kg} / \mathrm{m}^{2} \mathrm{~s}\end{array}$ & $\begin{array}{l}\text { - At } r / R=0.0 \text {, from } Z=1.52 \text { to } 9.42 \mathrm{~m} \\
\text { - At } r / R=0.74 \text {, from } Z=3.96 \text { to } 5.90 \mathrm{~m} \text { and } Z= \\
8.74 \text { to } 9.42 \mathrm{~m} \\
\text { - At } r / R=0.81 \text { to } 0.92 \text { from } Z=8.74 \text { to } 9.42 \mathrm{~m} \\
\text { - At } r / R=0.98 \text { from } Z=1.52 \text { to } 2.73 \mathrm{~m} \text { and from } \\
Z=6.43 \text { to } 9.42 \mathrm{~m}\end{array}$ & $\begin{array}{l}\text { - At } r / R=0.74 \text { from } Z=1.52 \text { to } 2.73 \mathrm{~m} \text { and } \\
\quad Z=6.42 \mathrm{~m} \\
\text { - At } r / R=0.81 \text { from } Z=1.52-6.43 \mathrm{~m} \\
\text { - At } r / R=0.87, Z=5.90 \mathrm{~m} \\
\text { - } r / R=0.92, Z=5.90 \mathrm{~m} \\
\text { - } r / R=0.98 \text { from } Z=5.13 \text { to } 5.90 \mathrm{~m}\end{array}$ & $\begin{array}{l}\text { - At } r / R=0.87, Z= \\
2.73 \mathrm{~m} \text { and } 6.43 \mathrm{~m}\end{array}$ & $\begin{array}{l}\text { - At } r / R=0.87, Z= \\
1.52 \mathrm{~m} \\
\text { - } \quad \text { At } r / R=0.92 \text { from } Z \\
=1.52 \text { to } 3.96 \text { and } Z= \\
6.43 \mathrm{~m} \\
\text { - } \text { At } r / R=0.98, Z= \\
3.96 \mathrm{~m}\end{array}$ \\
\hline $\begin{array}{c}U_{g}=8.0 \mathrm{~m} / \mathrm{s} \\
G_{s}=550 \\
\mathrm{~kg} / \mathrm{m}^{2} \mathrm{~s}\end{array}$ & $\begin{array}{l}\text { - At } r / R=0.0 \text { from } Z=1.52 \text { to } 9.42 \mathrm{~m} \\
\text { - At } r / R=0.74 Z=9.42 \mathrm{~m} \\
\text { - At } r / R=0.81 Z=9.42 \mathrm{~m}\end{array}$ & $\begin{array}{l}\text { - At } r / R=0.74, Z=5.13 \text { to } 6.34 \mathrm{~m} \\
\text { - At } r / R=0.81, Z=1.52 \text { to } 6.43 \mathrm{~m} \\
\text { - At } r / R=0.87, Z=5.13,6.34 \text { and } 9.42 \mathrm{~m} \\
\text { - At } r / R=0.92 \mathrm{~m}, Z=5.13,6.34 \text { and } 9.42 \mathrm{~m} \\
\text { - At } r / R=0.98, Z=5.13,6.34 \text { and } 9.42 \mathrm{~m}\end{array}$ & - & - \\
\hline
\end{tabular}

Table 4. Summary of the study findings on the characteristics of statistical parameters.

\begin{tabular}{|c|c|c|c|}
\hline \multirow[t]{2}{*}{ Parameter } & \multirow[t]{2}{*}{ Significance } & \multicolumn{2}{|l|}{ Observation } \\
\hline & & Centre/core region & Wall region \\
\hline $\begin{array}{l}\text { Standard } \\
\text { Deviation }\end{array}$ & $\begin{array}{l}\text { A measure of dispersion or fluctuation of solid } \\
\text { concentration }\end{array}$ & Low values with relatively flat profiles & Higher values towards the wall \\
\hline Skewness & $\begin{array}{l}\text { Measures the symmetrical properties or degree of } \\
\text { asymmetry of PDF around the mean }\end{array}$ & Higher and relatively flat profiles & $\begin{array}{l}\text { Decrease towards the wall with irregular } \\
\text { profiles }\end{array}$ \\
\hline Kurtosis & Indicates the tendency of the PDF to be peaked & $\begin{array}{l}\text { Higher values and generally flat } \\
\text { profiles }\end{array}$ & Lower, slightly decreases towards the wall \\
\hline Intermittent Index & $\begin{array}{l}\text { Shows the extent of gas-solid fluctuations or } \\
\text { gas-solid suspension flow segregation }\end{array}$ & $\begin{array}{l}\text { Relatively higher/lower values and } \\
\text { regular flat profiles }\end{array}$ & $\begin{array}{l}\text { Irregular profiles, Slightly increase towards } \\
\text { the wall }\end{array}$ \\
\hline $\begin{array}{l}\text { Coefficient of } \\
\text { Variation }\end{array}$ & $\begin{array}{l}\text { A measure of relative dispersion of a distribution. } \\
\text { It indicates variability or scattering tendency }\end{array}$ & Relatively higher and regular profiles & Decreases towards the wall \\
\hline $\begin{array}{l}\text { Average Absolute } \\
\text { Deviation }\end{array}$ & $\begin{array}{l}\text { Estimates the width of data around the average } \\
\text { values }\end{array}$ & $\begin{array}{l}\text { Constant, higher or lower values with } \\
\text { regular profiles }\end{array}$ & $\begin{array}{l}\text { Irregular profiles, relatively } \\
\text { increasing/decreasing towards wall }\end{array}$ \\
\hline $\begin{array}{l}\text { Probability } \\
\text { Density Function }\end{array}$ & $\begin{array}{l}\text { Indicates the distribution property of solid } \\
\text { concentration }\end{array}$ & $\begin{array}{l}\text { Tall and narrow left peak with longer } \\
\text { tails to the right }\end{array}$ & $\begin{array}{l}\text { Single or double peaks with tails towards } \\
\text { the right }\end{array}$ \\
\hline
\end{tabular}


- The flow non-uniformities in the bottom and developing flow section increase with increase in superficial gas velocity at constant solid flux due to the increase in particle interactions and disorders of the solid particles in the gas-solid suspension.

- The wall region along the axial direction from the bottom to the top section of the riser has positive skewed, single and double peaked PDF profiles indicating coexistence of both dilute and dense suspension flow.

These conclusions show the strength of statistical analysis as a technique for comprehensive understanding of the gas-solid flow dynamics in the High Flux CFB riser systems using solid concentration signals.

\section{Conflicts of Interest}

The authors declare no conflicts of interest regarding the publication of this paper.

\section{References}

[1] Manyele, S.V., Zhu, J.-X., Khayat, R.E. and Pärssinen, J.H. (2006) Analysis of the Chaotic Dynamics of a High-Flux CFB Riser Using Solids Concentration Measurements. China Particuology, 4, 136-146. https://doi.org/10.1016/S1672-2515(07)60253-X

[2] De Castilho, G.J. and Cremasco, M.A. (2012) Comparison of Downer and Riser Flows in a Circulating Bed by means of Optical Fiber Probe Signals Measurement. Procedia Engineering, 42, 295-302. https://doi.org/10.1016/j.proeng.2012.07.420

[3] You, J., Wang, D. and Zhu, C. (2009) Entrance Effects on Gas-Solid Riser Flow Structure. Industrial \& Engineering Chemistry Research, 48, 310-319. https://doi.org/10.1021/ie8004868

[4] Cheng, Y., Wei, F., Yang, G. and Jin, Y. (1998) Inlet and Outlet Effects on Flow Patterns in Gas-Solid Risers. Powder Technology, 98, 151-156. https://doi.org/10.1016/S0032-5910(98)00030-8

[5] Grace, L.R., Avidan, A.A. and Knowlton, T.M. (1997) Circulating Fluidized Beds. Blackie Academic \& Professional, London, UK.

[6] Wang, C. (2013) High Density Gas-Solid Circulating Fluidized Bed Riser and Downer Reactors. Ph.D. Thesis, University of Western Ontario, Ontario, Canada.

[7] Manyele, S.V., Zhu, J. and Zhang, H. (2003) Analysis of the Microscopic Flow Structure of a CFB Downer Reactor Using Solids Concentration Signals. International Journal of Chemical Reactor Engineering, 1, 1-17. https://doi.org/10.2202/1542-6580.1108

[8] Qiu, G., Ye, J. and Wang, H. (2015) Investigation of Gas-Solid Flow Characteristics in a Circulating Fluidized Bed with Annular Combustion Chamber by Pressure Measurements and CPFD Simulation, Chemical Engineering Science, 134, 433-447. https://doi.org/10.1016/j.ces.2015.05.036

[9] Jin, Y., Zhu, J. and Yu, Z. (1997) Novel Configurations and Variants, In: Grace, J.R., Avidan, A.A. and Knolton, T.M., Eds., Circulating Fluidized Beds, Blackie Academic \& Professional, London, 525-567. https://doi.org/10.1007/978-94-009-0095-0_16

[10] Basu, P. (2006) Combustion and Gasification in Fluidized Beds. Taylor \& Francis 
Group, Llc, Boca Raton, Florida, USA. https://doi.org/10.1201/9781420005158

[11] Johnsson, J., Zijerveld, R.C., Schouten, J.C., van den Bleek, C.M. and Leckner, B. (2000) Characterization of Fluidization Regimes by Time-Series Analysis of Pressure Fluctuations. International Journal of Multiphase Flow, 26, 663-715. https://doi.org/10.1016/S0301-9322(99)00028-2

[12] Zhu, H. and Zhu, J. (2007) Flow Structures in the Bottom Region of Riser. Refereed Proceedings of the 12 th International Conference on Fluidization-New Horizon in Fluidization Engineering, Vancouver, 13-17 May 2007, Canada Art. 9, 87-94.

[13] Luckos, A., Coetzer, R. and Mostert, A. (2013) Description of Pressure Fluctuations in a Circulating Fluidized Bed by Statistical Analysis. Referred Proceedings of the 10 th International Conference on Circulating Fluidized Beds and Fluidization Technology, Sun River, 1-5 May 2011, ECI Symposium Series, Volume RP7. http://dc.engconfintl.org/cgi/viewcontent.cgi?article $=1095 \&$ context=cfb10

[14] Manyele, S.V., Pärssinen, J.H. and Zhu, J.-X. (2002) Characterizing Particle Aggregates in a High-Density and High-Flux CFB Riser. The Chemical Engineering Journal, 88, 151-161. https://doi.org/10.1016/S1385-8947(01)00299-6

[15] Yang, J. (2013) Studies on Microscopic Flow Structures Inside a Rectangular Circulating Bed through Image Analysis. Ph.D. Thesis, University of Western Ontario, Canada.

[16] Wang, C., Zhu, J., Barghi, S. and Li, C. (2014) Axial and Radial Development of Solids Holdup in a High Flux/Density Gas-Solids Circulating Fluidized Bed. Chemical Engineering Science, 108, 233-243. https://doi.org/10.1016/j.ces.2013.12.042

[17] Wei, F., Lin, H., Cheng, Y., Wang, Z. and Jin, Y. (1998) Profiles of Particle Velocity and Solids Fraction in a High-Density Riser. Powder Technology, 100, 183-189. https://doi.org/10.1016/S0032-5910(98)00139-9

[18] Marzocchella, B., Zijerveld, R.C. Schouten, J.C. and van den Bleek, C.M. (1997) Chaotic Behaviour of Gas-Solids Flow in the Riser of a Laboratory Scale Circulating Fluidized Bed. AIChE Journal, 43, 1458-1468. https://doi.org/10.1002/aic.690430609

[19] Mann, P.S. (2010) Introductory Statistics. John Willey \& Sons Inc., New York.

[20] Van Ommen, J.R., Sasic, S., van der Schaaf, J., Gheorghiu, S., Johnsson, F. and Coppens, M.O. (2011) Time-Series Analysis of Pressure Fluctuations in Gas-Solid Fluidized Beds: A Review. International Journal of Multiphase Flow, 37, 403-428. https://doi.org/10.1016/j.ijmultiphaseflow.2010.12.007

[21] Manyele, S.V. and Zhu, J.-X. (2001) Radial and Non-Uniformity Index (RNI) in Fluidized Beds and Multphase Flow Syatems. The Canadian Journal of Chemical Engineering, 79, 203-213. https://doi.org/10.1002/cjce.5450790203

[22] Issangya, A.S., Grace, J.R., Bai, D. and Zhu, J. (2000) Further Measurements of Flow Dynamics in High-Density Circulating Fluidized Bed. Powder Technology, 111, 104-113. https://doi.org/10.1016/S0032-5910(00)00246-1

[23] Manyele, S.V. (2008) Accuracy Analysis for Kolmogrov Entropy Used I Studying the Chaotic Dynamics of CFB Reactors Based on Solids Concentration Fluctuations. Tanzania Journal of Engineering and Technology, 2, 22-35. 